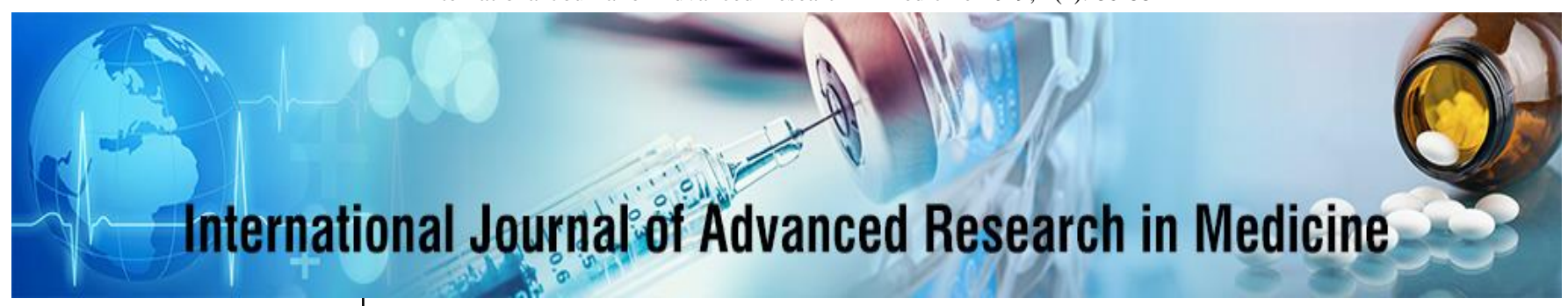

E-ISSN: 2706-9575

P-ISSN: 2706-9567

www.medicinepaper.net/ IJARM 2019; 1(1): 86-88 Received: 17-05-2019

Accepted: 20-06-2019

Khulood Abdulrazzaq Mohammed

Ministry of Health-Baghdad Medical Office-Karkh,

Baghdad, Iraq

Iman Oleiwi Murad Al-Khuzaie Ministry of Health - Baghdad Medical office - Al-Russafa, Fatima Al-Zahraa Maternity Hospital for Women and Children, Baghdad, Iraq

Haider Ali Mehdi Al-Remahi Ministry of Health-Baghdad Medical office-Al-Russafa, Fatima Al-Zahraa Maternity Hospital for Women and Children, Baghdad, Iraq
Corresponding Author: Khulood Abdulrazzaq Mohammed

Ministry of Health-Baghdad Medical Office-Karkh,

Baghdad, Iraq

\section{Gynecology policy clinic incontinence situations and quality of life examination}

\section{Khulood Abdulrazzaq Mohammed, Iman Oleiwi Murad Al-Khuzaie and Haider Ali Mehdi Al-Remahi}

DOI: $\underline{\text { https://doi.org/10.22271/27069567.2019.v1.i2b.23 }}$

\begin{abstract}
Gynecological complaints are highly severe in general population. Are common problems. Disease aspect of incontinence which is a gynecological problem, is closely related to the social situation of women. While the problem in rural areas is seen as a natural problem due to aging, a doctor is not consulted; incontinence, deep depression in urban and especially working women feeling of loneliness and contraction in social relations (urine smell, feeling of wetness) leading to consult a doctor for treatment at an earlier stage.

In this study, incontinence status in women who came to gynecology outpatient clinics and quality of life. Research University Medical Faculty Hospital Obstetrics and Gynecology Department. Accepted to participate in the study, selected by simple random method 100 women were collected and data were collected with the help of questionnaire form. As a result of data evaluation, $391 \%$ of women unintentionally urinary incontinence and urinary incontinence, but only $30.7 \%$ of this problem doctor. Hundred points of women's quality of life scale When the average score on the physical, 73 (80.80) and social they scored higher in the function fields (65.25); role limitation (emotional) (18.69) and role limitation (physical) (39.25). It has been identified.
\end{abstract}

Keywords: Gynecology policy, incontinence situations, life examination

\section{Introduction}

Healthy living is the most important of societies since the beginning of humanity has been the target. Health services developed in this direction; individual, family and to protect, improve and improve the health of society (Biçer et al., 2001) ${ }^{[7]}$. The most important when improving public health one of the targets is the 'healthy woman' phenomenon. Different health problems men and women affect the way (Arslan, 2001) ${ }^{[3]}$. Women in different stages of development Different problems are gaining weight. Szellikie climacterium period women, if the necessary measures are not taken, the quality of life is low they are condemned to live (Biçer et al. 2001) ${ }^{[7]}$. How gynecological problems affect patients' quality of life the results of protective wax and medical treatments, always discussed by experts different ways to measure (Güçsavaş, 1986) ${ }^{[13]}$. Incontinence The fact that a very small proportion of women receive medical help part of this process is forced to remain hidden. (Edward, 1999; Harris, 1999) ${ }^{[10,14]}$, Epidemiological studies, women in men 2 to 5 times more urinary incontinence (Davilla 1994, Locher, Burgio 1996, Kocagöz, Eroğlu 2002) ${ }^{[9,18] .}$ Orin is incontinence incidence with arthritis with age, urinary incontinence not only in older women, but also in young and middle aged populations can be seen (Kocagoz, Eroglu 2002) ${ }^{[18]}$. Orinary incontinence is a common social disorder in women of all ages. As a result of involuntary incontinence, causing hygienic and hygienic problems. (Arisan 1991, Berek 1998, Cisnisci et al. 1996, Norton 1990) ${ }^{[6,20]}$. Infection of patients who have not been treated with urinary incontinence, ü Skin problems such as citation; addiction to bed and catheterization at home problems such as later observed (Baurn, et al., 1991) ${ }^{[5]}$. In addition, patients' sexual life, daily work and home activities which affected; social and physical influences; It is known that they are unconsciously restricted and have nutritional problems. Fear, shy, loneliness, bad smell from themselves because of the environment abstraction or people avoiding them, feeling of pollution, precipitation feeling, anxiety incontinence individuals encounter psychological are some of the problems. Especially for menopausal women in hospitals and nursing homes incontinence, which is one of the most common causes of an important economic problem due to hygienic pads and medical interventions (Nas et al. 1996; Yalcin, 2000, Ergen, 2002) ${ }^{[19,11] .}$ 
The most effective of nursing services to women with gynecological problems in order to be presented in a format, and individuals aspects. In addition, these problems knowing to what extent it affects the quality of life of women, ensure that they approach the problem consciously and provide quality service, increasing the patient satisfaction and quality of health services. It will increase. In addition, family relations and public health positively affected.

\section{Research objective}

This study was carried out on the basis of quality-healthy living incontinent living status, quality of life levels and life. The aim of this study was to determine the factors affecting quality levels.

\section{Data collection method and data collection}

The data of the research is related to the subject by the researchers. Questionnaire prepared as a result of research and publications Short Form-36 (SF-36) scale for determining quality of life and quality of life using. The data were collected between 01.01.2018 and 31.03.2018 out of the women who applied to the polyclinic for examination selected by non-probable sampling method and accepted to participate in the research 100 women were collected using face to face interview technique. The questionnaire was used to determine the sociodemographic characteristics of women, problems of incontinence and life three levels of questions to determine quality levels. It was formed. Short Form used to determine quality of life levels-36 (SF-36) scale measures the health status of individuals in special diseases or disorders was developed in 1987 by Ware. Validity-reliability of the study despite scale; to define the health status of individuals in essence, to describe changes in health due to minor health conditions in society (Ruta et al. 1994). Also; gynecological validity and reliability of quality of life in women it has been shown to be an appropriate scale (Karayurt, 1997) ${ }^{[16]}$.

In addition, in clinical practice and research, health policies and general population surveys. Other features that have been arranged. Scale and validity reliability in 1991 by Pinar 50 cardiology, 50 hemodialysis, 80 Diabetes mellitus patients. According to this; patient groups Crohnbach's Alpha, which expresses the internal consistency of the scale regardless of the scale. Value was found 92 (Pinar, 1991).

\section{Results and Recommendations}

With the change in social roles, every day of life. It is expected to be active and productive in the field. Developing countries health problems that are still taboo are women who like urinary incontinence difficulties in life, late medical treatment, serious health problems. According to the results obtained from the research

It has been made.

1. To investigate the effect of ariner incontinence in clinical setting nurses should be allowed. Urinary incidence of women in clinical setting methods of coping with incontinence, nurse and sharing conditions with doctors, urinary incidence in men and women approaches to male and female patients with incontinence problems, the effect of different types of urinary incontinence on female life, nurses' attitude towards urinary incontinence, childbirth effect of urinary incontinence on urinary incontinence, nurses' knowledge about urinary incontinence investigate,

2. urinary incontinence; half of women in a period of their lives Introducing the public as a common medical problem affecting,

3. In all studies and publications on women's health, urinary Incontinence issues effectively,

4. Women risk factors, problems caused by urinary incontinence and information about treatment and treatment, Midwives and nurses working in obstetrics and gynecology departments, urinary providing information about incontinence

\section{References}

1. Anafata K, Beduk Y, Gogus O, Arikan N. Urge Incontinence in Women. Basic Orology, Sun Bookstore, 1998, 413-445.

2. Human K. Gynecology. 3, Bs. Celtuk Printing, Istanbul, 1991.

3. Arslan D. Women's Human and Health Rights, Current Medicine. 2001; 6(1):2-22.

4. Arslan E et al. Orinar and Fecal Incontinence of Elderly People Living in Retirement Homes Prevalence And Its Effect On Quality of Life, 2nd National Urogynecology Congress Abstract The Book, Istanbul, 2002, 48,

5. Baum N, Suarez G, Appell R. Oriner Incontinence, Syndrome, 1991, 53-58.

6. Berek JS. Novak Gynecology. Trans. Ahmet Erk, bs. Nobel Bookstores, Istanbul, 1998, 12.

7. Biçer T, Bebis H, Inanc N. Primary Health Care and Community Health Examination of Nursing Education, Nursing Forum. 2001; 4(2-3):7-14.

8. Brown JS, Grady D, Quaslander JG, Herzog Varner RE, Posner SF. Urinary Incontinence and Associated Risk Factors Postmenopausal Women, Obstetrics and Gynecology, 1990, 94(I).

9. Davila W. Orinar Incontinence in Women, Syndrome, 1994, 39-43.

10. Eclward M. Urological, Disorders of Women and Women in Urology, The Journal of Urology. 1999; 161(1):4.

11. Ergene A. Women's Incontinence, Geriatrics 2002, Gökçe Y (Ed.), HOGEBAM, Turgut Publishing and Tie. Inc. Istanbul, 2002, 103-106.

12. Fidaner H. Measuring Life Limits, Psychiatry Psychology Psychopharmacology Magazine. 1999; 7(2):14-22

13. Gucsav N. Women's and Women's Health Problems Women-specific Infections, Turkish Journal of Nurses. 1986; 36(2):52-54.

14. Harris A. Impact of Urinary Incontinence on the Quality of Life of Women, British Journal of Nursing. 1999; 8(6):375-380

15. Thin H. New Approach to Urinary Incontinence Complaints, $2003 . \quad$ Bitp: //www.kadmlar.com.kadmandfamilyhealthcare.

16. Karayurt Ö. Pre-operative Different Training Programs Investigation of Effects on Anxiety and Pain Levels. V. National Nursing Congress Book, Izmir: Dokuz Eylül Only. Rectorate Printing House, 1997, 37-46.

17. Coriander HA et al. Basic Gynecology and Obstetrics. Sun Bookstore, Ankara, 1996.

18. Kocagoz S, Eroglu K. Prevalence of Stress Oriner Incontinence in Women and Do It Determination of 
Affecting Factors, Journal of Nursing Research. 2002; 4(1):29-39

19. Nas T, Guner H, Taner Z et al. Diagnosis of Urinary Incontinence in Women Evaluation of the Reliability of History, Gynecology Obstetrics. 1996; 6(1):7-77.

20. Norton PA. Prevention and Sedat Impact of Urinary Incontinence in Women, Clinical Obstetrics and Gynecology, 1990, 33(2). 